\title{
French-American-British Classification
}

National Cancer Institute

\section{Source}

National Cancer Institute. French-American-British Classification. NCI Thesaurus. Code C91220.

A classification system for acute myeloid leukemias, acute lymphoblastic leukemias, and myelodysplastic syndromes. It is based on the morphologic and cytochemical evaluation of bone marrow and peripheral blood smears. 